\title{
Correction to: Risk exposure assessment of per- and polyfluoroalkyl substances (PFASs) in drinking water and atmosphere in central eastern China
}

\author{
Zhibo $\mathrm{Lu}^{1,2} \cdot$ Rong $\mathrm{Lu}^{1,2} \cdot$ Hongyuan Zheng ${ }^{1,2,3} \cdot$ Jing Yan $^{1,2} \cdot$ Luning Song $^{1,2} \cdot$ Juan Wang ${ }^{1,2} \cdot$ Haizhen Yang ${ }^{1,2}$. \\ Minghong $\mathrm{Cai}^{3}$
}

Published online: 5 March 2018

(C) Springer-Verlag GmbH Germany, part of Springer Nature 2018

\section{Correction to: Environ Sci Pollut Res https://doi.org/10.1007/s11356-017-0950-x}

The original publication of this paper contains a mistake.

The correct presentation of the $7^{\text {th }}$ Author is shown in this paper.

The original article has been corrected.

The online version of the original article can be found at https://doi.org/ 10.1007/s11356-017-0950-x

Minghong Cai

caiminghong@pric.org.cn

1 College of Environmental Science and Engineering, Tongji University, Shanghai 200092, China

2 State Key Laboratory on Pollution Control and Resource Reuse, Tongji University, Shanghai 200092, China

3 SOA Key Laboratory for Polar Science, Polar Research Institute of China, Shanghai 200136, China 